\title{
Influence of cavosurface angle on the stress concentration and gaps formation in class $\mathrm{V}$ resin composite restorations
}

\author{
Ayla Macyelle de Oliveira Correia ${ }^{a}$, Victoria Elisa Maciel Pereira ${ }^{a}$, Eduardo Bresciani ${ }^{\mathrm{a}}$, \\ Jeffrey A. Platt ${ }^{\mathrm{b}}$, Alexandre Luiz Souto Borges ${ }^{\mathrm{c}}$, Taciana Marco Ferraz Caneppele ${ }^{\mathrm{a}}$
}

\begin{abstract}
${ }^{a}$ Department of Restorative Dentistry, São Paulo State University - UNESP, Institute of Science and Technology, São José dos Campos, São Paulo, Brazil

${ }^{b}$ Department of Biomedical and Applied Sciences, Division of Dental Biomaterials, Indiana University School of Dentistry (IUSD), Indianapolis, IN, USA

${ }^{c}$ Department of Dental Materials and Prosthodontics, São Paulo State University UNESP, Institute of Science and Technology, São José dos Campos, São Paulo, Brazil
\end{abstract}

\section{CORRESPONDING AUTHOR}

Ayla Macyelle de Oliveira Correia

Department of Restorative Dentistry - São Paulo State University - UNESP, Institute of Science and Technology.

Av. Eng. Francisco José Longo, 777 - Jardim São Dimas. São José dos Campos/SP, Brazil. 12245-000.

Phone: + 5512 99666-7745

E-mail: aylamacyelle@hotmail.com

\section{MAILING ADDRESS}

aylamacyelle@hotmail.com

vick_pereira@hotmail.com

eduardob@ict.unesp.br

jplatt2@iu.edu

aleborges@ict.unesp.br

taciana@ict.unesp.br

This is the author's manuscript of the article published in final edited form as:

Correia, A. M. de O., Pereira, V. E. M., Bresciani, E., Platt, J. A., Borges, A. L. S., \& Caneppele, T. M. F. (2019). Influence of cavosurface angle on the stress concentration and gaps formation in class V resin composite restorations. Journal of the Mechanical Behavior of Biomedical Materials, 97, 272-277. https://doi.org/10.1016/j.jmbbm.2019.05.034 


\begin{abstract}
The study aimed to evaluate the influence of cavosurface angle on stress concentration and gap formation in class $\mathrm{V}$ restorations. Cylindrical cavities $3 \mathrm{~mm}$ in diameter were prepared in forty-five bovine incisors, changing only the angle of the bur in relation to the flat surface of the tooth. The cavities maintained the same volume $\left(17.67 \mathrm{~mm}^{3}\right)$. The samples were divided according to the cavosurface angle, into three groups $(n=15): 90^{\circ}$, $120^{\circ}, 135^{\circ}$. After adhesive application (Futurabond U, VOCO), the cavity was filled with bulk placement of a resin composite (GrandioSO, VOCO). The teeth were analyzed with stereomicroscopy. Data of marginal gap formation were statistically analyzed with a oneway analysis of variance (ANOVA) followed by Tukey tests (significance level: $\alpha=0.05$ ). Finite element analysis (FEA) was used to study residual stress in these geometries and to correlate those stresses with experimentally measured gap formation. The elastic modulus and polymerization shrinkage were determined for FEA. Residual shrinkage stresses were expressed in maximum principal stress (MPS). There was a significant difference in the gap formation among the groups $(p=0.001)$. A significantly lower marginal gap formation was found for $120^{\circ}$ and $135^{\circ}$ angles, with no significant difference between them. The cavosurface angle at $90^{\circ}$ caused substantially higher stresses, in the restoration interface, with greater marginal gap. For the $120^{\circ}$ and $135^{\circ}$ angles, the stress concentrations were smaller and were located in the dental structure. The cavosurface angle influenced the marginal gap formation and stress concentration.
\end{abstract}

Keywords: dental marginal adaptation; composite resins; cervical lesion; finite element analysis; residual stress. 


\section{Introduction}

Resin composites as direct restorative materials are widely used in dentistry due to their esthetics and adhesion to tooth structure. However, this material still show drawbacks related to polymerization shrinkage and stress induced within the material, at the tooth/restoration interface, and in the tooth structure (Krejci et al., 2005; Yamamoto et al., 2009; Ferracane and Hilton, 2016), which may influence the clinical performance of restorations (Braga et al., 2005; Ferracane and Hilton, 2016; Rizzante et al., 2019). The compromised adhesion along the restoration margin or at restoration/tooth interface, resulting in gap, stains, microleakage or cuspal movement has been considered a consequence of polymerization shrinkage (Krejci et al., 2005; Yamamoto et al., 2009; Bicalho et al., 2014; Kim and Park, 2014; Kim et al., 2015).

The polymerization shrinkage is an inherent characteristic of the resin composites (Braga et al., 2005; Rizzante et al., 2019), which depends on a number of factors including the material composition, the degree of conversion, the volume, and the elastic modulus (Braga et al., 2005; Braga et al., 2012; Benetti et al., 2014; Kim and Park, 2014; Van Dijken and Lindberg, 2015; Ferracane and Hilton, 2016; Han et al., 2019). The fact is that stress cannot be considered an isolated factor when it comes to the marginal adaptation of resin composite restorations; other factors, such as thermal changes and occlusal loads (Kim and Park, 2014; Van Dijken and Lindberg, 2015), placement of resin composite (Furness et al., 2014; Yoshimine et al., 2015; Correia et al., 2018; Alqudaihi et al., 2019), curing technique (dos Santos et al., 2007; Gamarra et al., 2018), cavity size and geometry (Braga et al., 2006; Borges et al., 2014; Han et al., 2016; Han et al., 2019) also may have a significant effect.

There are several reports on marginal gap formation and factors affecting its development (Versluis et al., 1996; Peutzfeldt and Asmussen, 2004; Braga et al., 2006; dos Santos et al., 2007; Furness et al., 2014; Benetti et al., 2015; Alqudaihi et al., 2019; Han et al., 2019). Different techniques and introducing of new polymeric systems have not been effective in eliminating the shrinkage stress and, thus, in reducing the gap formation (Versluis et al., 1996; Yoshimine et al., 2015; Correia et al., 2018; Gamarra et al., 2018; Han et al., 2019; Alqudaihi et al., 2019; He et al., 2019). However, studies suggest that marginal bevels can reduce or eliminate the microleakage and gaps associated with resin composite restorations (Opdam et al., 1998; Coelho-de-Souza et 
al., 2008; Coelho-de-Souza et al., 2010; Borges et al., 2014). Another possible approach for controlling the effects of polymerization stress is related to the design of the cavity. Borges et al. (2014) reported that different cavosurface margins of class V restorations result in different stress concentration sites within the restoration during the polymerization of the resin composite. This means that if the stress concentration can be directed away from the margin by increasing the angle of the cavosurface bevel, the degradation of the adhesive interface could be reduced.

Therefore, this study was designed to evaluate the influence of cavosurface angle on gap formation and the stress concentration in class $\mathrm{V}$ restorations, using experimental testing and a method of mathematical three-dimensional (3D) finite element analysis (FEA) simulating the same experimental conditions. The hypotheses tested was that the stress concentration and gaps formation in class $\mathrm{V}$ resin composite restorations are not affected by cavosurface angle.

\section{Materials and methods}

\subsection{Study design}

Three different cavosurface angles were tested in this study to determine the gap formation in class $\mathrm{V}$ restorations. Bovine incisors with Class $\mathrm{V}$ cavities were restored using an adhesive and resin composite. Gap formation was examined with stereomicroscopy. Polymerization shrinkage and elastic modulus for the composite were determined. Finally, shrinkage stresses and the stresses during compressive loading were evaluated by FEA using Maximum principal stress (MPS).

\subsection{Tooth selection and cavity preparation}

Forty-five fresh, non-damaged bovine incisors were collected for this study. Bovine teeth were used instead of human teeth due easy to obtain and standardize. In addition, histochemical and morphology studies show that their properties are very similar to human teeth (Nakamichi et al., 1983; Almeida et al., 2009; Teruel et al., 2015; Soares et al., 2016). The incisal portion and roots were removed and teeth were stored in $0.1 \%$ thymol solution under refrigeration at $4^{\circ} \mathrm{C}$ until used. 
The enamel surface was ground flat using 600-grit aluminum oxide abrasive papers of (FEPA-P, Struers, Ballerup, Denmark), in a polishing device (Pantec Polipan 2, São Paulo, SP, Brazil) under water irrigation for $30 \mathrm{~s}$. After this, the teeth were positioned with the enamel surface facing down and embedded in acrylic resin (Jet-Clássico, São Paulo, SP, Brazil).

Teeth were randomly divided into three groups $(n=15)$, according to the cavosurface angle: $90^{\circ}, 120^{\circ}$ and $135^{\circ}$. Class V cavities were created on each tooth using a $3 \mathrm{~mm}$ diameter spherical bur (KG Sorensen, Barueri, SP, Brazil) adapted to a cutting machine whose base allows angulation adjustment. The cavities were prepared under abundant air-water coolant. The depth of the preparation was modified and controlled by the apparatus to keep a standardized volume $\left(17.67 \mathrm{~mm}^{3}\right)$ independent of the angulation of the sample. Figure 1 shows the depth $(\mathrm{mm})$ and $\mathrm{C}$-factor of the cavities for the three cavosurface angle groups.

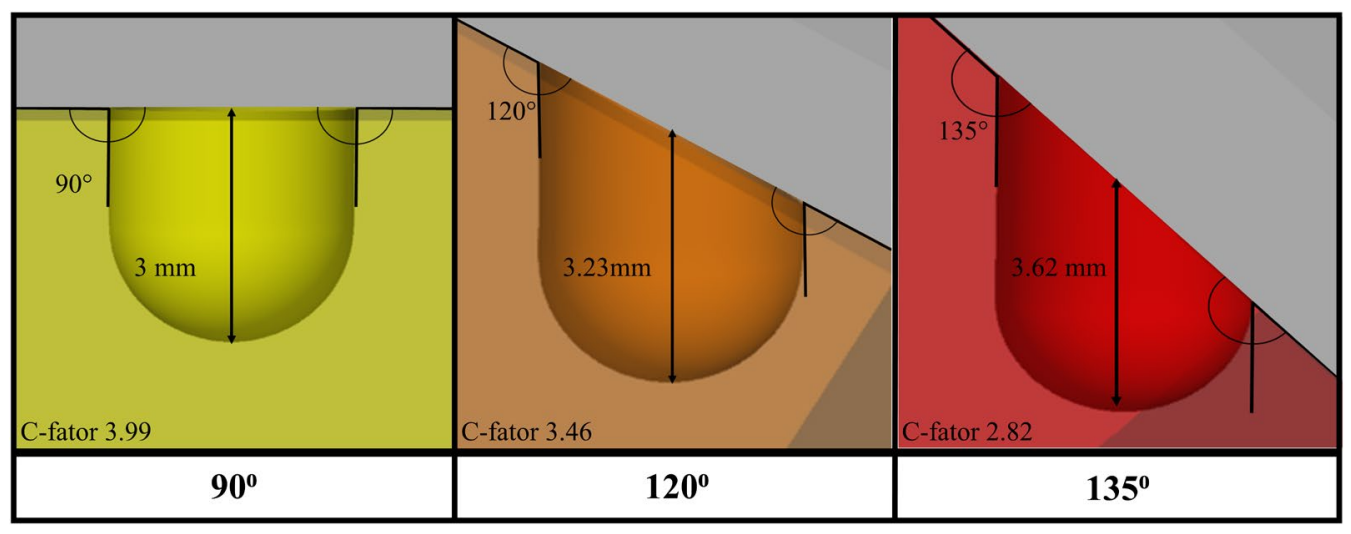

Figure 1. The geometry of three cavities studied according to depth and cavosurface angle.

\subsection{Restorative procedures}

The materials used in this study were adhesive system Futurabond $U$ - Single Dose - (VOCO, Cuxhaven, Germany) and the resin composite GrandioSO (shade A3.5, VOCO, Cuxhaven, Germany). Their composition and manufacturer information are listed in Table 1. Each cavity was gently dried with cotton swabs to leave a moist dentin surface. The adhesive system was applied in one coat for $20 \mathrm{~s}$, followed by gentle air-drying for 5 $\mathrm{s}$ and then light-cured with a Radii-cal LED (SDI, Australia) at $1200 \mathrm{~mW} / \mathrm{cm}^{2}$ for $15 \mathrm{~s}$. The irradiance was evaluated with a radiometer (L.E.D, Demetron; Kerr Corp, Orange, 
CA, USA) in each light activations to ensure the same conditions for every specimen. The cavity was filled with bulk placement of the direct resin composite. Then, a mylar strip was positioned over the material and pressured with a glass slide. The light tip of Radiical LED was positioned on the glass slide, perpendicular to the specimen surface, and the polymerization was performed for $40 \mathrm{~s}$. The teeth were stored in ultrapure water at $37^{\circ} \mathrm{C}$ for $24 \mathrm{~h}$.

Table 1. Technical information about the material used in the study

\begin{tabular}{c|c|c|c}
\hline Material & Manufacturer & Composition & Lot No. \\
\hline GrandioSO & $\begin{array}{c}\text { Voco, Cuxhaven, } \\
\text { Germany }\end{array}$ & Bis-GMA, Bis-EMA, TEGDMA & 1029391 \\
\hline Futurabond U & $\begin{array}{c}\text { Voco, Cuxhaven, } \\
\text { Germany }\end{array}$ & $\begin{array}{c}\text { 2-Hydroxyethyl methacrylate, Bis- } \\
\text { propyl dihydrogen phosphate, } \\
\text { urethane dimethacrylate }\end{array}$ & 130847 \\
\hline
\end{tabular}

Abbreviations: Bis-GMA, bisphenol A glycidyl methacrylate; Bis-EMA, bisethyl methacrylate; TEGDMA, triethylene glycol dimethacrylate; HEDMA, hexane diol dimethacrylate.

After this, the labial surface was polished using aluminum oxide abrasive papers in sequential grits of 1200, 2400, and 4000 (FEPA-P, Struers, Ballerup, Denmark), in a polishing device (Pantec Polipan 2, Panambra Industrial e Técnica SA, São Paulo, SP, Brazil), under water irrigation for $60 \mathrm{~s}$ each. Then, the specimens were placed in distilled water and cleaned ultrasonically for $10 \mathrm{~min}$.

\subsection{Marginal gap assessment}

A stereomicroscope (Discovery V20, Zeiss; Gottingen, Germany) was used to evaluate gap width at a magnification of 50X. The gap measurement was performed only at the margin of the restoration where the cavosurface angle was $90^{\circ}, 120^{\circ}$ and $135^{\circ}$, which corresponds to $1 \mathrm{~mm}$ of the cavity perimeter. For each specimen, an average of the three largest gaps was then calculated. All measurements of marginal gap formation were 
performed with the AxioVision Software (Zeiss; Gottingen, Germany), using a reference scale visible of this software, by one operator (V.E.M.P).

\subsection{Statistical analysis}

Means and standard deviations were determined for each condition studied. Gap marginal data were normally distributed as determined by the Kolmogorov-Smirnov test so one-way analysis of variance (ANOVA) followed by Tukey test was applied, with the significance level significance of 5\%.

\subsection{Elastic modulus}

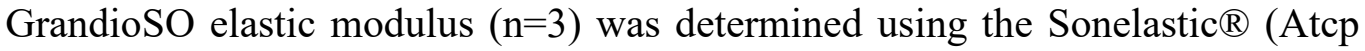
Engenharia Física, São Carlos, Brazil). Bar-shaped specimens (40 x 6 × 2 mm) were set in transverse vibration with a single-pulse excitation generated using small a hammer driven by an electromagnet. The signal produced was captured by a microphone underneath the sample by a special signal analyzer, and the fundamental frequency under flexure was displayed on the screen of the apparatus. The Poisson's Ratio was automatically calculated by the software. These data were used in the shrinkage stress calculations.

\subsection{Polymerization shrinkage}

Polymerization shrinkage $(n=3)$ was measured using a video imaging device (AcuVol, Bisco Inc, Schaumburg, IL, USA) in volumetric reconstruction mode (Tiba et al., 2005). The specimens, approximately $10 \mu \mathrm{l}$ of the resin composite, were manually shaped into a semi-sphere $(4.8 \mathrm{x} \quad 1.3 \mathrm{~mm})$ and placed on the rotational polytetrafluoroethylene pedestal inside the Acuvol chamber in front of the CCD camera. The specimens were imaged at a distance of $10 \mathrm{~cm}$ and subsequently irradiated for $40 \mathrm{~s}$ using the same LED curing light as for restoration procedures. The light tip was positioned $1 \mathrm{~mm}$ from the top of the resin composite. The images were digitized and analyzed with the proprietary image processing software. The volume of the specimens before and after curing was recorded as V1 and V2, respectively. The polymerization shrinkage was calculated as follows:

$$
\mathrm{PS} \%=[(\mathrm{V} 1-\mathrm{V} 2) / \mathrm{V} 1] \mathrm{X} 100
$$


The values obtained were used in the shrinkage stress calculations.

\subsection{Residual stress calculation: Finite Element Analysis}

To calculate corresponding residual stress, a 3D finite element simulation was carried out for all the restorations. For the geometric model, a bovine dentin square section was created in the CAD (Computer Aided Design) Rhinoceros software (McNeel North America, Seattle, EUA) with dimensions and conditions the same as the teeth in the experimental test. The enamel thickness was $0.5 \mathrm{~mm}$ and dentin $9.5 \mathrm{~mm}$. Thus, the preparation was simulated made by a $3 \mathrm{~mm}$ diameter spherical bur, such that the volume cross-sectional area of restorative material $\left(17.67 \mathrm{~mm}^{3}\right)$ was maintained. Schematic illustrations of the performed procedures are shown in Figure 1.

These CAD models were imported as STP (Standard for the Exchange of Product Model Data) files into ANSYS software (ANSYS 17.2, ANSYS Inc, Houston, TX, USA) and the mesh was created with tetrahedral quadratic elements. Tests varying the size of elements were carried out until $10 \%$ of convergence of the results was reached, which determined that the ideal element size be $0.3 \mathrm{~mm}$. All materials were considered homogenous, linearly elastic, and isotropic. Their mechanical properties are summarized in Table 2.

Table 2. Mechanical properties of the materials used in the numerical simulations

\begin{tabular}{c|c|c|c|c|c}
\hline $\begin{array}{c}\text { Material/ } \\
\text { structure }\end{array}$ & $\begin{array}{c}\text { Elastic } \\
\text { Modulus } \\
(\mathbf{G P a})\end{array}$ & $\begin{array}{c}\text { Poisson's } \\
\text { Ratio }\end{array}$ & $\begin{array}{c}\text { Coefficient of } \\
\text { Thermal } \\
\text { Expansion, } \\
\text { mm/ } \boldsymbol{C}^{\circ} \text {; } \\
\text { Reference } \\
\text { Temperature: } \\
\mathbf{2 5}^{\circ} \boldsymbol{C}\end{array}$ & $\begin{array}{c}\text { Volumetric } \\
\text { Post-gel } \\
\text { Shrinkage } \\
(\%)\end{array}$ & Reference \\
\hline Enamel & 50.1 & 0.3 & - & - & $\begin{array}{c}\text { Lin and } \\
\text { Douglas, 1994 }\end{array}$ \\
\hline $\begin{array}{c}\text { Axson F16 } \\
\text { Polyurethane }\end{array}$ & 3.6 & 0.3 & - & $\begin{array}{c}\text { Lin and } \\
\text { Douglas, 1994 }\end{array}$ \\
\hline GrandioSO & 21.62 & 0.24 & 0.0000136 & $2.56 \%$ & $\begin{array}{c}\text { Souza et al., } \\
2015\end{array}$ \\
\hline
\end{tabular}

* Information obtained in laboratory tests described previously. 
The restoration-tooth interface in all the models were considered perfectly bonded. Polymerization shrinkage was simulated by thermal analogy (Borges et al., 2014). The temperature was reduced by $1^{\circ} \mathrm{C}$ and the linear shrinkage value (post-gel shrinkage) was entered as the coefficient of linear thermal expansion.

A linear static structural analysis was performed to calculate the stress concentration in the cavity. The MPS was used to express the stress conditions in the adhesive interface.

\section{Results}

\subsection{Marginal Gap}

Mean values and standard deviations for the marginal gap of Class V restorations are presented in Table 3. ANOVA showed a significant effect of the cavosurface angle concerning gap formation $(\mathrm{p}=0.001)$.

Table 3. Marginal gap formation in each cavosurface angle (mean values and standard deviations)

\begin{tabular}{cc}
\hline Cavosurface angle & Marginal gap $(\mu \mathrm{m})$ \\
\hline $90^{\circ}$ & $12.05 \pm 6.06 \mathrm{a}^{*}$ \\
$120^{\circ}$ & $3.82 \pm 2.07 \mathrm{~b}$ \\
$135^{\circ}$ & $3.11 \pm 2.61 \mathrm{~b}$ \\
\hline
\end{tabular}

*Different letters mean the statistical difference.

The marginal gap was significantly lower in the group with cavosurface angle of $120^{\circ}$ and $135^{\circ}$. Representative images of the marginal gap in each group are shown in Figure 2.
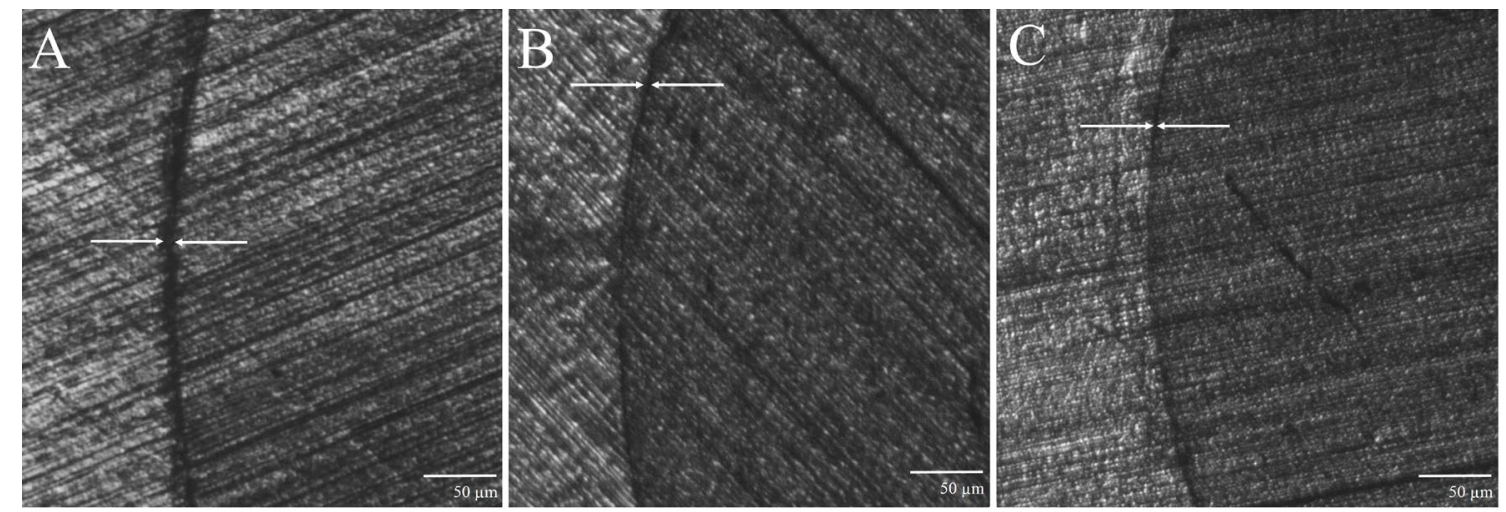
Figure 2. Representative images are showing gap marginal of restorative with cavosurface angle in $90^{\circ}(\mathrm{A}), 120^{\circ}(\mathrm{B}), 135^{\circ}(\mathrm{C})$. The arrows corresponds the marginal gaps in restoration-tooth interface.

\subsection{Finite element analysis}

Stress concentration for all groups are shown in Figure 3. Compared to the other two groups, the cavosurface angle in $90^{\circ}$ resulted in highest stress, presenting tensile stress in the adhesive interface and inside the cavities, while angulations of $120^{\circ}$ and $135^{\circ}$ generated the lowest stress values along the interface and cavity wall.

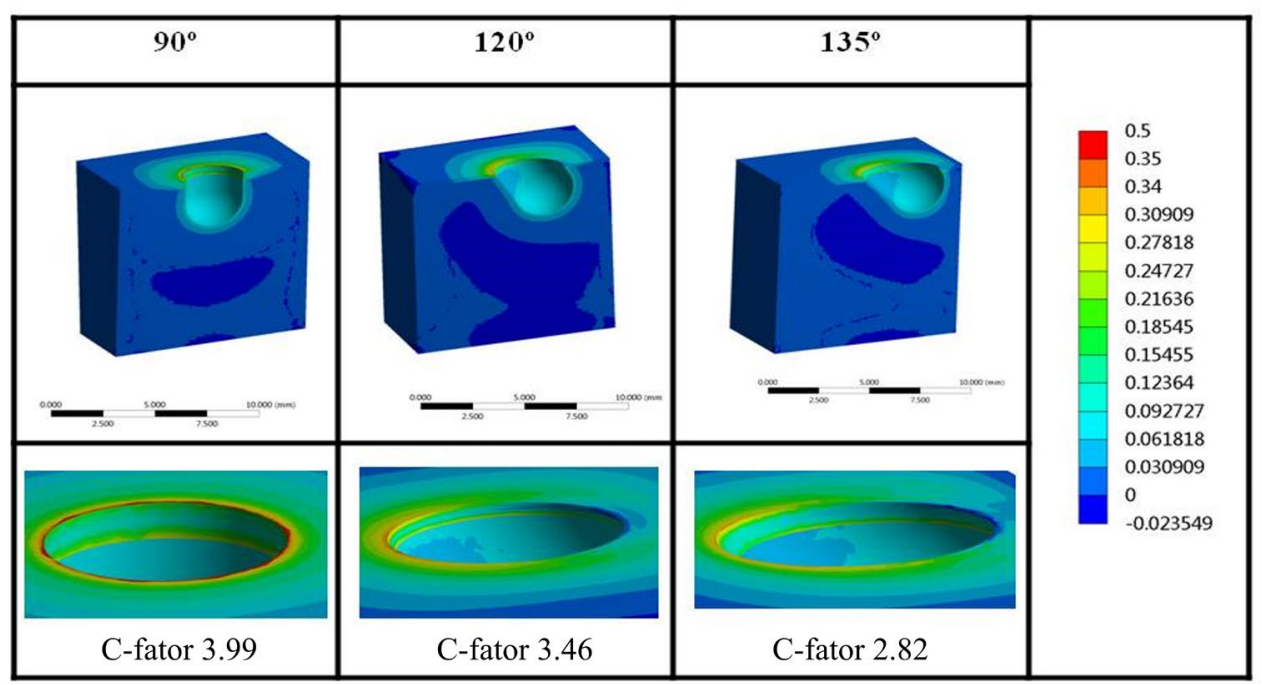

Figure 3. Stress concentration (MPa) calculated by finite element analysis by Maximum principal stress (MPS) according to the cavosurface angle.

\section{Discussion}

Bench tests are fundamental to assess dental structures and restorative materials because they assess controllable factors related to polymerization shrinkage and consequently, marginal gap formation. However, with these studies, it is not possible to obtain information about the internal behavior of the restoration or to determine the polymerization stresses (Bicalho et al., 2014). Thus, this study used FEA to assess the stress concentration and to ensure that the results of the experimental test were justified and validated. The present study confirmed a significant influence of the cavosurface 
angle on the marginal gap formation and distribution of shrinkage stresses in the restoration/tooth interface. The results showed the higher the angle formed at the cavosurface margin, the lower the marginal gap formation and stress concentration. Therefore, the hypothesis tested was rejected.

The distribution of shrinkage stress and gap formation depends on an interplay between several factors, such as physical properties and structural features of resin composite, cavity and restorative procedure (Peutzfeldt and Asmussen, 2004; Braga et al., 2005; Bicalho et al., 2014; Han et al., 2016; Correia et al., 2018). In this investigation, the factors related to the cavity and the restorative procedure were to keep constant. Thus, during the preparation of the cavity, the depth of bur penetration had to be altered according to each group to obtain a constant volume $\left(17.67 \mathrm{~mm}^{3}\right)$ for all restorations. Furthermore, the same resin composite and the adhesive system were chosen. One important characteristic that was be considered in the choice of GrandioSO composite is their high elastic modulus. This property have a significant influence on the polymerization shrinkage (Benetti et al., 2014; Kim and Park, 2014; Han et al., 2019). It has been reported that materials with high elastic modulus lead to higher stress development, and consequently, in higher marginal gap formation (Ferracane, 2005; Braga et al., 2012; Benetti et al., 2014). Based on this information and with the goal of assessing the influence of cavosurface angle on stress concentration and gap formation in class V restorations, GrandioSO was used because would have to higher probability of stress development and marginal gap formation. In relation to the placement technique, all cavities were restored with bulk placement of this composite. According to the literature, the bulk placement reduces or prevents the formation of air bubbles or other defects present in the matrix during its application (Papadogiannis et al., 2015; Par et al., 2015). Besides that, the presence of the final gap in the restoration is more dependent on the insertion of the material in the cavity than with polymerization shrinkage (Almeida Junior et al., 2017). Light-curing was performed with a high-performance LED curing unit, and the irradiance was monitored.

The volume standardization was chosen to isolate the variable of interest (cavosurface angle) and study their individual or combined effects in marginal gap formation. In a previous study, deep restorations showed high shear stress, regardless of their width (Braga et al., 2006; Boaro et al., 2014). The effect of volume in these cavities 
was evident, presenting greater correlation with stress concentration than the C-factor. It was also previously suggested that the microleakage is largely influenced by the volume of the material (Braga et al., 2006; Rodrigues et al., 2012). When the C-factor is constant, the higher the quantity of resin, the higher the stress concentration, and consequently the higher the risk of microleakage (Braga et al., 2013; Borges et al., 2014).

In the present study, the cavity with higher C-Factor showed the higher peak stress (Figure 3). The finding is consistent with the classical C-factor theory, which proposed that the higher the C-factor, the higher the stress (Feilzer et al., 1987), and is in agreement with previous findings (Braga et al., 2013; Boaro et al., 2014). However, in this case, the stress values cannot be predicted by only the C-Factor or quantity of resin because of the influence of cavosurface angle. In a previous study of shrinkage stress in class $\mathrm{V}$ restorations unbeveled, the peak stress was close to the cavosurface margin (Borges et al., 2014). When beveled, the peak stress on the enamel and dentin walls decreased, suggesting that the magnitude of shrinkage stress was mainly dependent of the cavosurface angle.

Marginal bevelling is a procedure that can reduce marginal gap formation, improve fracture resistance (Coelho-de-Souza et al., 2008; Soliman et al., 2016), and result in improved esthetics (Aida et al., 2016). Marginal gap formation is the result of a localized failure due to stress concentration or insufficient bond strength (Braga et al., 2006). According to research conducted by Peutzfeldt and Asmussen (2004), there is a proportional relationship between the polymerization shrinkage and marginal gap formation. During the polymerization process, covalent chemical bonds occur, and monomers link (Kim et al., 2015). Polymerization shrinkage may cause internal stresses that are transferred to the material interface (Ferracane, 2005). When the shrinkage stress surpasses the bond strength, a fracture of the adhesive interface can occur, resulting in marginal gap formation. This could allow the penetration of saliva, bacteria, and other irritating substances (Kim et al., 2015). Borges et al. (2014), in their mathematical model, reported a direct relationship between cavosurface angle and stress concentration. It was shown that the smaller the angle of tooth structure, the higher the stress concentration. Also, it is important to point out that the beveling increase the bond area of enamel and promotes notably more adhesion than dentin. In our study, higher stress concentration, in the restoration interface, and marginal gap were evidenced where the cavosurface angle 
was $90^{\circ}$. For the $120^{\circ}$ and $135^{\circ}$ angles, the stress concentrations were smaller and were located in the dental structure, being less critical, which could explain the results of our experimental phase. Therefore, the cavosurface angle seems a valid parameter to predict marginal gap formation only in cases where restorations of similar volume and same cavity shape are compared.

The experimental findings, validated by the FEA results, also explain the trends of marginal gap formation versus cavosurface angle, that angle can be considered as a relevant factor in predicting the stress in a class V cavity (Borges et al., 2014). They also provide new insights into stress concentration during resin composite polymerization. Therefore, further investigations are suggested to refine the concepts presented in this study, and their results need to be confirmed in clinical trials.

\section{Conclusion}

Despite the limitations of this study, and based on our laboratory and FEA analyses, it can be concluded that the cavosurface angle studied influenced the marginal gap formation and the stress concentration. The smallest stresses were found at cavosurface angles of $120^{\circ}$ or $135^{\circ}$. Overall, the study suggested that marginal gap formation is strongly related to the cavosurface angles of the cavity.

\section{Acknowledgements}

This study was supported by the National Council for Scientific and Technological Development (CNPq) under grants 30764 from Brazil.

\section{References}

Aida, A., Nakajima, M., Seki, N., Kano, Y., Foxton, R.M., Tagami, J., 2016. Effect of enamel margin configuration on color change of resin composite restoration. Dent. Mater. J. 35, 675-683.

Almeida Junior, L.J.D.S., Penha, K.J.S., Souza, A.F., Lula, E.C.O., Magalhães, F.C., Lima, D.M., Firoozmand, L.M., 2017. Is there correlation between polymerization shrinkage, gap formation, and void in bulk fill composites? A $\mu \mathrm{CT}$ study. Braz. 
Oral Res. 31, e100.

Almeida, K.G., Scheibe, K.G., Oliveira, A.E., Alves, C.M., Costa, J.F., 2009. Influence of human and bovine substrate on the microleakage of two adhesive systems. J. Appl. Oral Sci. 17, 92-96.

Alqudaihi, F.S., Cook, N.B., Diefenderfer, K.E., Bottino, M.C., Platt, J.A., 2019. Comparison of internal adaptation of bulk-fill and increment-fill resin composite materials. Oper. Dent. 44, e32-e44.

Benetti, A.R., Havndrup-Pedersen, C., Honoré, D., Pedersen, M.K., Pallesen, U., 2015. Bulk-Fill resin composites: polymerization contraction, depth of cure, and gap formation. Oper Dent. 40, 190-200.

Benetti, A.R., Peutzfeldt, A., Lussi, A., Flury, S., 2014. Resin composites: Modulus of elasticity and marginal quality. J. Dent. 42, 1185-1192.

Bicalho, A.A., Valdívia, A.D., Barreto, B.C., Tantbirojn, D., Versluis, A., Soares, C.J., 2014. Incremental filling technique and composite material—part II: shrinkage and shrinkage stresses. Oper Dent. 39, e83-e92.

Boaro, L.C., Brandt, W.C., Meira, J.B., Rodrigues, F.P., Palin, W.M., Braga, R.R., 2014. Experimental and FE displacement and polymerization stress of bonded restorations as a function of the C-Factor, volume and substrate stiffness. J. Dent. 42, 140-148.

Borges, A.L., Borges, A.B., Xavier, T.A., Bottino, M.C., Platt, J.A., 2014. Impact of quantity of resin, C-factor, and geometry on resin composite polymerization shrinkage stress in class V restorations. Oper. Dent. 39, 144-151.

Braga, R.R., Ballester, R.Y., Ferracane, J.L., 2005. Factors involved in the development of polymerization shrinkage stress in resin-composites: a systematic review. Dent. Mater. 21, 962-970.

Braga, R.R., Boaro, L.C., Kuroe, T., Azevedo, C.L., Singer, J.M., 2006. Influence of cavity dimensions and their derivatives (volume and " $\mathrm{C}$ " factor) on shrinkage stress development and microleakage of composite restorations. Dent. Mater. 22, 818-823.

Braga, R.R., Koplin, C., Yamamoto, T., Tyler, K., Ferracane, J.L., Swain, M.V., 2013. Composite polymerization stress as a function of specimen configuration assessed by crack analysis and finite element analysis. Dent. Mater. 29, 1026-1033. 
Braga, R.R., Yamamoto, T., Tyler, K., Boaro, L.C., Ferracane, J.L., Swain, M.V., 2012. A comparative study between crack analysis and a mechanical test for assessing the polymerization stress of restorative composites. Dent. Mater. 28, 632-641.

Coelho-de-Souza, F.H., Camacho, G.B., Demarco, F.F., Powers, J.M., 2008. Fracture resistance and gap formation of MOD restorations: influence of restorative technique, bevel preparation and water storage. Oper. Dent. 33, 37-43.

Coelho-de-Souza, F.H., Klein-Júnior, C.A., Camargo, J.C., Beskow, T., Balestrin, M.D., Demarco, F.F., 2010. Double-blind randomized clinical trial of posterior composite restorations with or without bevel: 6-month follow-up. J. Contemp. Dent. Pract. $11,1-8$.

Correia, A.M.O., Tribst, J.P.M., Matos, F.S., Platt, J.A., Caneppele, T.M.F., Borges, A.L.S., 2018. Polymerization shrinkage stresses in different restorative techniques for non-carious cervical lesions. J. Dent., 76, 68-74.

dos Santos, G.O., da Silva, A.H., Guimarães, J.G., Barcellos, A.A., Sampaio, E.M., da Silva, E.M., 2007. Analysis of gap formation at tooth-composite resin interface: effect of C-factor and light-curing protocol. J. Appl. Oral Sci. 15, 270-274.

Feilzer, A.J., De Gee, A.J., Davidson, C.L., 1987. Setting stress in composite resin in relation to configuration of the restoration. J Dent. Res. 66, 1636-1639.

Ferracane, J.L., 2005. Developing a more complete understanding of stresses produced in dental composites during polymerization. Dent. Mater. 21, 36-42.

Ferracane, J.L., Hilton, T.J., 2016. Polymerization stress--is it clinically meaningful?. Dent. Mat. 32, 1-10.

Furness, A., Tadros, M.Y., Looney, S.W., Rueggeberg, F.A., 2014. Effect of bulk/incremental fill on internal gap formation of bulk-fill composites. J. Dent. 42, 439-449.

Gamarra, V.S.S., Borges, G.A., Júnior, L.H.B., Spohr, A.M., 2018. Marginal adaptation and microleakage of a bulk-fill composite resin photopolymerized with different techniques. Odontology. 106, 56-63.

Han, S.H., Sadr, A., Shimada, Y., Tagami, J., Park, S.H., 2019. Internal adaptation of composite restorations with or without an intermediate layer: Effect of polymerization shrinkage parameters of the layer material. J. Dent. 80, 41-48.

Han, S.H., Sadr, A., Tagami, J., Park, S.H., 2016. Internal adaptation of resin composites 
at two configurations: influence of polymerization shrinkage and stress. Dent. Mater. 32, 1085-1094.

He, J., Garoushi, S., Säilynoja, E., Vallittu, P.K., Lassila, L., 2019. The effect of adding a new monomer "Phene" onthe polymerization shrinkage reduction of a dental resin composite. Dent. Mater. 35, 627-635.

Kim, R.J., Kim, Y.J., Choi, N.S., Lee, I.B., 2015. Polymerization shrinkage, modulus, and shrinkage stress related to tooth-restoration interfacial debonding in bulk-fill composites. J. Dent. 43, 430-439.

Kim, H.J., Park, S.H., 2014. Measurement of the internal adaptation of resin composites using micro-CT and its correlation with polymerization shrinkage. Oper. Dent. 39, 57-70.

Krejci, I., Planinic, M., Stavridakis, M., Bouillaguet, S., 2005. Resin composite shrinkage and marginal adaptation with different pulse-delay light curing protocols. Eur. J. Oral Sci. 113, 531-536.

Lin, C.P., Douglas, W.H., 1994. Structure-property relations and crack resistance at the bovine dentin-enamel junction. J. Dent. Res. 73, 1072-1078.

Nakamichi, I., Iwaku, M., Fusayama, T., 1983. Bovine teeth as possible substitutes in the adhesion test. J. Dent. Res. 62, 1076-1081.

Opdam, N.J, Roeters, J.J., Kuijs, R., Burgersdijk, R.C., 1998. Necessity of bevels for box only Class II composite restorations. J. Prosthet. Dent. 80, 274-279.

Papadogiannis, D., Tolidis, K., Gerasimou, P., Lakes, R., Papadogiannis, Y., 2015. Viscoelastic properties, creep behavior and degree of conversion of bulk fill composite resins. Dent Mater. 31, 1533-1541.

Par, M., Gamulin, O., Marovic, D., Klaric, E., Tarle, Z., 2015. Raman spectroscopic assessment of degree of conversion of bulk-fill resin composites - changes at 24 hours post cure. Oper. Dent. 40, e92-e101.

Peutzfeldt, A., Asmussen, E., 2004. Determinants of in vitro gap formation of resin composites. J. Dent. 32, 109-115.

Rizzante, F.A.P., Duque, J.A., Duarte, M.A.H., Mondelli, R.F.L., Mendonça, G., Ishikiriama, S.K., 2019. Polymerization shrinkage, microhardness and depth of cure of bulk fill resin composites. Dent. Mater. J. 1-8. [Epub ahead of print]. doi: 10.4012/dmj.2018-063 
Rodrigues, F.P., Silikas, N., Watts, D.C., Ballester, R.Y., 2012. Finite element analysis of bonded model Class I "restorations" after shrinkage. Dent. Mater. 28, 123-132.

Soares, F.Z.M., Follak, A., da Rosa, L.S., Montagner, A.F., Lenzi, T.L., Rocha, R.O., 2016. Bovine tooth is a substitute for human tooth on bond strength studies: A systematic review and meta-analysis of in vitro studies. Dent. Mater. 32, 13851393.

Souza, A.C., Xavier, T.A., Platt, J.A., Borges, A.L., 2015. Effect of base and inlay restorative material on the stress distribution and fracture resistance of weakened premolars. Oper. Dent. 40, e158-e166.

Soliman, S., Preidl, R., Karl, S., Hofmann, N., Krastl, G., Klaiber, B., 2016. Influence of cavity margin design and restorative material on marginal quality and seal of extended class II resin composite restorations in vitro. J. Adhes. Dent. 18, 7-16.

Tiba, A., Charlton, D.G., Vandewalle, K.S., Ragain, J.C., 2005. Comparison of two videoimaging instruments for measuring volumetric shrinkage of dental resin composites. J. Dent. 33, 757-763.

Teruel, J.D., Alcolea, A., Hernández, A., Ruiz, A.J., 2015. Comparison of chemical composition of enamel and dentine in human, bovine, porcine and ovine teeth. Arch. Oral Biol. 60, 768-775.

van Dijken, J.W., Lindberg, A., 2015. A 15-year randomized controlled study of a reduced shrinkage stress resin composite. Dent. Mater. 31, 1150-1158.

Versluis, A., Douglas, W.H., Cross, M., Sakaguchi, R.L., 1996. Does an incremental filling technique reduce polymerization shrinkage stresses?. J. Dent. Res. 75, 871878.

Yamamoto, T., Ferracane, J.L., Sakaguchi, R.L., Swain, M.V., 2009. Calculation of contraction stresses in dental composites by analysis of crack propagation in the matrix surrounding a cavity. Dent. Mater. 25, 543-550.

Yoshimine, N., Shimada, Y., Tagami, J., Sadr, A., 2015. Interfacial adaptation of composite restorations before and after light curing: effects of adhesive and filling technique. J. Adhes. Dent. 17, 329-336. 